\title{
Desenvolvimento de mudas de manjericão (Ocimum basilicum L.) em função do recipiente e do tipo e densidade de substratos
}

\author{
MAGGIONI, M.S. ${ }^{1}$; ROSA, C.B.C.J.'; ROSA JUNIOR, E.J. ${ }^{1}$; SILVA, E.F.'; ROSA, Y.B.C.J. ${ }^{2 *}$; SCALON, S.P.Q. ${ }^{1}$; \\ VASCONCELOS, A.A. ${ }^{3}$ \\ ${ }^{1}$ Universidade Federal da Grande Dourados. Dourados-Brasil. ; 2 Universidade Federal da Grande Dourados. \\ Dourados-Brasil *yararosa@ufgd.edu.br; ${ }^{3}$ Universidade Federal de Viçosa. Viçosa-Brasil
}

\begin{abstract}
RESUMO: Uma das etapas mais importantes na produção do manjericão é o desenvolvimento das mudas. Nesta etapa, o cuidado com o recipiente e o substrato é essencial, pois afetam diretamente o crescimento e a arquitetura do sistema radicular, bem como, o fornecimento de nutrientes. Assim, o objetivo deste trabalho foi avaliar o desenvolvimento de mudas de manjericão (Ocimum basilicum L.) influenciadas pelo tipo e densidade de diferentes substratos, cultivadas em bandejas de poliestireno com diferentes números de células. O experimento foi conduzido na área de Jardinocultura da Universidade Federal da Grande Dourados (UFGD) em Dourados - MS. O delineamento experimental utilizado foi em blocos casualizados com cinco repetições, sendo os tratamentos dispostos em esquema fatorial $3 \times 3 \times 5$, sendo três tipos de bandejas de poliestireno expandido com 72, 128 e 200 células com volumes internos de 124,3; 44,8 e $17,7 \mathrm{~mL}$, respectivamente. Três tipos de substratos comerciais (PlantMax Florestais ${ }^{\circledR}$; Tropstrato Vida Verde ${ }^{\circledR}$ e PlantMax Hortaliças $\left.\mathrm{HA}^{\circledR}\right)$, e cinco densidades de substratos $(0,36$; 0,$42 ; 0,48 ; 0,54$ e $0,60 \mathrm{~kg} \mathrm{dm}^{-3}$ ). Decorridos 78 dias após a emergência das plantas avaliou-se alturas das plantas, massa fresca e seca da parte aérea e sistema radicular, e comprimento de raízes. A produção de mudas comerciais de manjericão (Ocimum basilicum L.) foi melhor com o uso do substrato Tropstrato Vida Verde ${ }^{\circledR}$ na bandeja de 72 células associado com a densidade de $0,47 \mathrm{~kg} \mathrm{dm}^{-3}$.
\end{abstract}

Palavras-chave: Ocimum basilicum, substrato comercial, número de células.

ABSTRACT: Development of basil seedlings(Ocimum basilicum $L$.)in different density and type of substrates and trays. One of the most important stages in the production of basil is the development of seedlings. In this step, care with the container and the substrate is essential, because it directly affects the root growth and architecture, as well as the supply of nutrients. Thus, the objective of this study was to evaluate the development of basil seedlings (Ocimum basilicum L.) influenced by the type and density of different substrates, grown in polystyrene trays with different cell numbers. The experiment was conducted at the Gardening area of the Federal University of Grande Dourados (UFGD) inDourados-MS, Brazil.The experimental design was a randomized block with fivereplications, with treatments arranged in a $3 \times 3 \times 5$ factorial design, with three types of polystyrene trays with 72,128 and 200 cells, with internal volumes of 124.3; 44.8 and $17.7 \mathrm{~mL}$, respectively. We used three types of substrates (PlantMax Florestais ${ }^{\circledR}$; Tropstrato Vida Verde ${ }^{\circledR}$ and PlantMax Hortaliças $\left.\mathrm{HA}^{\circledR}\right)$ and five densities of substrate $(0.36,0.42$, $0.48,0.54$ and $0.60 \mathrm{~kg} \mathrm{dm}^{-3}$ ). After 78 days of plant emergence, we evaluatedthem regarding: plant height, fresh and dry shoot and root, and root length. The commercial production of basil seedlings was improved with the use of the substrate Tropstrato Vida Verde ${ }^{\circledR}$ in a 72 cell tray associated with the density of $0.47 \mathrm{~kg} \mathrm{dm}^{-3}$.

Keywords: Ocimum basilicum, commercial substrate, cell number

\section{INTRODUÇÃO}

O manjericão (Ocimum basilicum L.), pertencente à família Lamiaceae, é uma planta

anual ou perene, dependendo do local em que é cultivado. No Brasil, o manjericão é cultivado 
principalmente por pequenos produtores rurais para a comercialização da planta como condimento (Teixeira et al., 2002). As propriedades medicinais atribuídas à espécie são as de sedativo suave ajudando a combater enxaquecas, gastrites, alivia dores de garganta e de dente, cicatriza aftas, controla tosses, resfriados ou crises de bronquite (Lorenzi \& Matos, 2002; Mosca \& Loiola, 2009; Brito \& Senna-Valle, 2011). Estudos recentes têm demonstrado seu grande potencial antimicrobiano e antioxidante (Sartoratotto et al., 2004; Politeo et al., 2007).

Uma das etapas mais importantes do sistema produtivo é a produção de mudas, a qual influencia diretamente o desempenho final das plantas. Nesta etapa, o uso de recipientes como bandeja de poliestireno tem se mostrado eficiente sob vários aspectos, tais como economia de substrato e de espaço dentro da casa-de-vegetação, menor gastos com produtos fitossanitários, produção de mudas com alta qualidade e elevado índice de pegamento após o transplante. Além do tamanho do recipiente, o tipo de substrato a ser utilizado é importante, pois estes fatores afetam diretamente o desenvolvimento e a arquitetura do sistema radicular, bem como, o fornecimento de nutrientes. Analisando diversos substratos, Trani et al. (2007) constataram que o substrato Plantmax PXHA (Eucatex) demonstrou ser mais eficiente para produção de mudas de alface com melhor qualidade em bandejas de 128 células. Para mudas de beterraba, Echer et al. (2007), observaram que ao utilizar bandejas com 128 células e os substratos Plantimax e Mogimax obtiveram mudas maiores e de melhor qualidade.

Para maximizar a produção de mudas no viveiro, tem-se utilizado bandejas com células de menor volume possível. Porém, a redução de volume pode prejudicar a qualidade da muda e, consequentemente, a produtividade das espécies. Nesmith \& Duval (1998), em ampla revisão bibliográfica sobre uma variedade de recipientes de diferentes tamanhos usados para transplantes de culturas hortículas e flores, relatam que a restrição radicular, observada em recipientes de pequenos volumes, pode afetar o crescimento, a fotossíntese, o teor de clorofila nas folhas, a absorção de nutrientes e água, a respiração, o florescimento, bem como a produção. A maior massa de raízes em recipientes pequenos contribui para a redução do espaço poroso gerando maior competição por oxigênio. As mudas com sistema radicular restringido, quando transplantadas, são frequentemente incapazes de compensar a evapotranspiração, mesmo se bem irrigadas após o transplante (Pereira \& Martinez, 1999).

O tamanho das células da bandeja interfere na produção de mudas de diversas olerícolas. Trabalhos com alface (Trani et al., 2004), cebola (Reghin et al., 2007a), chicória (Reghin et al., 2006, Reghin et al., 2007b), e tomate cereja (Lima et al., 2009) demonstraram que as mudas dessas plantas apresentam melhor qualidade quando produzidas em células com maior volume. Objetivando estudar a viabilidade da utilização de bandejas de poliestireno expandido com 72 e 128 células, na produção de mudas de batata-doce com boa sanidade, utilizando o substrato comercial Plantmax ${ }^{\circledR}$, Rós \& Narita (2011) constataram que o tipo de bandeja apresentou influência na produtividade de ramas (peso de ramas frescas), a qual foi favorecida pela bandeja de 72 células com aumento na produção de mudas $16 \%$ em relação às de 128 células. Também observando interação entre o volume da célula e o substrato, Rodrigues et al. (2010) observaram que o uso de bandejas maiores com 72 células com substrato contendo $7 \%$ de composto orgânico, foi a melhor opção para o crescimento e acúmulo de biomassa em mudas de tomateiro.

Todavia, trabalhos analisando bandejas e tipos de substrato comerciais que beneficiem o manjericão são escassos. Assim, este trabalho tem como objetivo avaliar o desenvolvimento de mudas de manjericão (Ocimum basilicum L.) influenciadas pelo tipo e densidade de diferentes substratos, cultivados em bandejas de poliestireno com diferentes números de células.

\section{MATERIAL E MÉTODO}

O experimento com manjericão (Ocimum basilicum $\mathrm{L}$.) foi desenvolvido no período de março a junho de 2009, em viveiro na área de Jardinocultura, da Faculdade de Ciências Agrárias da Universidade Federal Grande Dourados, em Dourados-MS, situada nas coordenadas $22^{\circ} 13^{\prime} 16^{\prime \prime} S$ e $54^{\circ} 17^{\prime} 01^{\prime \prime} \mathrm{W}$ com altitude de $430 \mathrm{~m}$. O viveiro provido de tela de $50 \%$ de sombreamento propiciou, durante o período experimental, luminosidade média diária de 5300 lux, umidade relativa média de $72 \%$ e temperatura $21^{\circ} \mathrm{C}$ (média das mínimas) a $38^{\circ} \mathrm{C}$ (média das máximas).

O delineamento experimental utilizado foi em blocos casualizados com cinco repetições, sendo os tratamentos dispostos em esquema fatorial $3 \times 3 \times 5$, sendo três tipos de bandejas de poliestireno expandido com 200, 128 e 72 células com volumes internos de 17,7; 44,8 e 124,3 mL, respectivamente. Três tipos de substratos comerciais (PlantMax Florestais ${ }^{\circledR}$; Tropstrato Vida Verde ${ }^{\circledR}$ e PlantMax Hortaliças $\left.\mathrm{HA}^{\circledR}\right)$ e cinco densidades $(0,36 ; 0,42$; 0,$48 ; 0,54$ e $0,60 \mathrm{~kg} \mathrm{dm}^{-3}$ ) obtidas pelo uso de massa seca dos substratos dividida pelo volume interno das células das bandejas. 
As principais características dos substratos são apresentadas na Tabela 1.

Para cada tratamento utilizou-se duas sementes de manjericão por célula, semeadas a profundidade de $0,50 \mathrm{~cm}$ que após emitirem dois pares de folhas definitivas foram desbastadas, permanecendo uma planta por célula. Não foi realizada nenhuma fertilização adicional. As bandejas foram mantidas sobre as bancadas do viveiro e a irrigação foi realizada por meio de aspersão com lâmina diária de $6 \mathrm{~mm}$.

Decorridos 78 dias após a emergência avaliou-se a altura das plantas, com auxílio de régua graduada em $\mathrm{cm}$, do nível do substrato nas bandejas até a inflexão da folha mais alta. Posteriormente, as plantas foram removidas dos substratos e seccionadas separando-se a parte aérea do sistema radicular. As raízes foram lavadas para remover 0 substrato e pesadas obtendo-se sua massa fresca, a seguir, o seu comprimento foi calculado com a utilização da metodologia descrita por Marsh (1971) e por Tennant (1975). Para se obter a massa seca das partes, aérea e radicular, os materiais foram colocados para secar a $65{ }^{\circ} \mathrm{C} \pm 2{ }^{\circ} \mathrm{C}$, em estufa de ventilação forçada, até apresentarem massa constante.
Para análise dos resultados utilizou-se o aplicativo computacional SAEG (Ribeiro Júnior, 2001), e Sigma Plot 9.0 para confecção dos gráficos. Os dados foram submetidos análise de variância pelo teste $\mathrm{F}$ e quando significativos os efeitos foram comparados pelo teste Tukey, a 5\% de probabilidade, ou por regressão.

\section{RESULTADO E DISCUSSÃO}

Analisando as características agronômicas das mudas de manjericão, observou-se que houve interação entre substrato $x$ tipo de bandeja $(p>0,05)$ para a massa fresca e seca da parte aérea e do sistema radicular, altura das mudas e comprimento de raízes (Tabela 2). A densidade teve somente efeito isolado $(p>0,05)$ no sistema radicular e na altura das mudas (Tabela 2).

O substrato que proporcionou maior crescimento da parte aérea foi o Tropstrato Vida Verde ${ }^{\circledR}$ acondicionado na bandeja de 72 células, obtendo-se para massa fresca $0,82 \mathrm{~g}^{\text {planta }}{ }^{-1}$, massa seca $0,15 \mathrm{~g}$ planta $^{-1}$ e para altura das mudas 7,81 cm (Tabelas 3 e 4). Esta diferença de produção de massa fresca e seca da parte aérea além da superioridade do substrato Tropstrato

TABELA 1. Características dos substratos comerciais utilizados no experimento.

\begin{tabular}{|c|c|c|c|c|c|c|}
\hline \multicolumn{7}{|c|}{ PRINCIPAIS CARACTERÍSTICAS DOS SUBSTRATOS } \\
\hline Substratos & $\begin{array}{c}\text { U max. } \\
(\%)\end{array}$ & $\begin{array}{c}\text { CRA } \\
(\%)\end{array}$ & $\begin{array}{c}\text { pH } \\
\text { (em água) }\end{array}$ & $\begin{array}{c}\text { Densidade } \\
\left(\mathrm{kg} \mathrm{m}^{-3}\right)\end{array}$ & 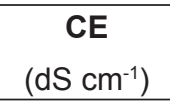 & Matérias primas* \\
\hline $\begin{array}{c}\text { PlantMax } \\
\text { Florestais }^{\circledR}\end{array}$ & 50 & 150 & $5,8( \pm 0,5)$ & 450 & $2,6( \pm 0,3)$ & $\begin{array}{l}\text { Casca de pinus } \\
\text { Vermiculita } \\
\text { Corretivo de acidez } \\
\text { Uréia } \\
\text { Sulfato de Amônio. } \\
\text { Superfosfato Simples } \\
\text { Formul. terceirizada }\end{array}$ \\
\hline $\begin{array}{c}\text { Tropstrato Vida } \\
\text { Verde }^{\circledR}\end{array}$ & 60 & 130 & $5,8( \pm 0,5)$ & 200 & $0,5( \pm 0,1)$ & $\begin{array}{l}\text { Casca de pinus } \\
\text { Vermiculita } \\
\text { Turfa } \\
\text { Superfosfato Simples } \\
\text { Nitrato de Potássio } \\
\text { Formul. terceirizada }\end{array}$ \\
\hline $\begin{array}{l}\text { P I a n t M a x } \\
\text { Hortaliças } \mathrm{HA}^{\circledR}\end{array}$ & 50 & 150 & $5,8( \pm 0,5)$ & 450 & $1,3( \pm 0,3)$ & $\begin{array}{l}\text { Casca de pinus, Vermiculita } \\
\text { Turfa } \\
\text { Corretivo de acidez } \\
\text { Superfosfato simples } \\
\text { Nitrato de potássio } \\
\text { Formul. terceirizada }\end{array}$ \\
\hline
\end{tabular}

U - Umidade; CRA - Capacidade de retenção de água; CE - Condutividade elétrica. As informações registradas na tabela são descritas na embalagem pelo fabricante. 
TABELA 2. Análise de variância das massas frescas (MFPA e MFSR) e secas (MSPA e MSSR) da parte aérea e do sistema radicular, comprimento de raízes (CSR) e altura de mudas de manjericão, produzidas em três substratos, três tipos de bandejas e cinco densidades. UFGD, Dourados, 2009.

\begin{tabular}{|c|c|c|c|c|c|c|c|}
\hline \multirow[b]{2}{*}{$\begin{array}{l}\text { Fonte de } \\
\text { Variação }\end{array}$} & \multirow[b]{2}{*}{ GL } & \multicolumn{6}{|c|}{ Quadrado Médio do Resíduo } \\
\hline & & MFPA & MSPA & MFSR & MSSR & $\begin{array}{c}\text { Comprimento de } \\
\text { raízes }\end{array}$ & Altura \\
\hline Bloco & 4 & $0,078^{\text {ns }}$ & $0,0012^{\mathrm{ns}}$ & $0,236^{\mathrm{ns}}$ & $0,0031^{\mathrm{ns}}$ & $52992,39^{\text {ns }}$ & $2,274^{\mathrm{ns}}$ \\
\hline Bandeja & 2 & $1,416^{* *}$ & $0,016^{* *}$ & $20,125^{* *}$ & $0,1999^{* *}$ & $3453978^{* *}$ & $77,205^{* *}$ \\
\hline Substrato & 2 & $3,660^{* *}$ & $0,0899^{* *}$ & $34,568^{* *}$ & $0,3690^{* *}$ & $658999^{* *}$ & 209,182 \\
\hline Densidade & 4 & $0,081^{\mathrm{ns}}$ & $0,0031^{\mathrm{ns}}$ & $0,583^{\text {ns * }}$ & $0,0127^{*}$ & $209897,5^{* *}$ & $5,964^{*}$ \\
\hline $\begin{array}{c}\text { Substrato x } \\
\text { Bandeja }\end{array}$ & 4 & $0,965^{* *}$ & $0,0191^{* *}$ & $9,853^{* *}$ & $0,129^{* *}$ & $1519136^{* *}$ & $20,911^{* *}$ \\
\hline $\begin{array}{l}\text { Bandeja x } \\
\text { Densidade }\end{array}$ & 8 & $0,053^{\text {ns }}$ & $0,0017^{\mathrm{ns}}$ & $0,4834^{\mathrm{ns}}$ & $0,00621^{\mathrm{ns}}$ & $69935,19^{\text {ns }}$ & $1,69^{\mathrm{ns}}$ \\
\hline $\begin{array}{l}\text { Substrato } x \\
\text { Densidade }\end{array}$ & 8 & $0,049^{\text {ns }}$ & $0,0008^{\mathrm{ns}}$ & $0,2087^{\mathrm{ns}}$ & $0,0055^{\mathrm{ns}}$ & $73789,51^{\mathrm{ns}}$ & $1,498^{\mathrm{ns}}$ \\
\hline $\begin{array}{l}\text { Subs } x \text { band } x \\
\text { densidade }\end{array}$ & 16 & $0,067^{\text {ns }}$ & $0,0009^{\mathrm{ns}}$ & $0,3556^{\mathrm{ns}}$ & $0,0072^{\text {ns }}$ & $56458,17^{\text {ns }}$ & $2,23^{\text {ns }}$ \\
\hline Resíduo & 177 & 0,047 & 0,0016 & 0,2843 & 0,0042 & 38898,19 & 1,9212 \\
\hline $\begin{array}{c}\text { Média geral } \\
\mathrm{CV}(\%)\end{array}$ & & $\begin{array}{c}0,36 \mathrm{~g} \\
42,0\end{array}$ & $\begin{array}{c}0,049 \mathrm{~g} \\
44,5\end{array}$ & $\begin{array}{c}0,92 \mathrm{~g} \\
31,1\end{array}$ & $\begin{array}{c}0,089 \mathrm{~g} \\
44,7\end{array}$ & $\begin{array}{c}359,17 \mathrm{~cm} \\
35,4\end{array}$ & $\begin{array}{c}4,94 \mathrm{~cm} \\
18,4\end{array}$ \\
\hline
\end{tabular}

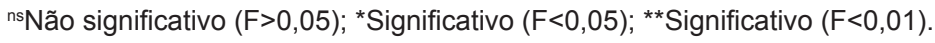

deve-se, provavelmente, ao volume da bandeja utilizada, uma vez que, a bandeja de 72 células (124,3 $\mathrm{mL})$, proporcionou maior volume de substrato explorado pelas raízes das mudas de manjericão que as demais bandejas (128 e 200 células). A densidade influenciou somente a altura das mudas de manjericão, sendo a altura máxima estimada $(5,15 \mathrm{~cm})$ obtida com a densidade de $0,49 \mathrm{~kg} \mathrm{dm}^{-3}$ (Figura 1 a).

Trabalhos analisando esses tipos de substratos são escassos na literatura, corroborando com esse resultados, Gordin et al. (2008) analisando diferentes combinações de substrato Comercial Vida Verde e húmus na formação de mudas de chicória, observaram que para as massas seca e fresca da parte aérea e altura de planta, o tratamento que apresentou melhores resultados foi o que utilizou $100 \%$ do substrato Vida Verde $₫$. Todavia, em experimento com alface crespa (cv. Vera), Trani et al. (2004), observaram melhores resultados com Plantmax HA frente aos três outros substratos avaliados (Hortimix folhosas, Golden Mix47 e Tropstrato Vida Verde Hortaliças), quanto à altura de planta e número de folhas. Aos 15 dias, mudas cultivadas em Plantmax já atingiram altura superior a $5 \mathrm{~cm}$, mínima necessária para o transplante aos 20-25 dias. Após dez dias, os autores confirmaram interferência do substrato no número de folhas, tal que aos 20 dias o Plantmax proporcionou maior número de folhas do que os demais substratos.

Assim como nesse experimento, o tamanho das células da bandeja interfere na parte aérea de diversas olerícolas. Resende et al. (2003), analisando a influência de tipos de bandeja e idade de transplante das mudas de alface tipo americana observaram que, em mudas com 30 dias as maiores massas frescas foram obtidas com as bandejas com menores número de células $(3,50 ; 2,23 \mathrm{e}$ $1,76 \mathrm{~g} \mathrm{planta}^{-1} \mathrm{com}$ as bandejas de 128; 200 e 288 células, respectivamente). Rodrigues et al. (2010) observaram que o uso de bandejas maiores com 72 células com substrato contendo $7 \%$ de composto orgânico, foi a melhor opção para o crescimento e acúmulo de biomassa em mudas de tomateiro.

Assim entende-se que, quanto menor for o espaço disponível às raízes e menor quantidade de substrato mais difícil será o suprimento de fatores que garantam o crescimento otimizado e desenvolvimento normal da muda. Segundo Silva et al. (2000) e Menezes Júnior et al. (2000), quando há maior volume de substrato envolvendo o sistema radicular, torna-se mais fácil o suprimento de fatores ótimos de produção para o crescimento e desenvolvimento das mudas.

Analisando o comprimento, massa fresca e seca das raízes observou-se novamente 
TABELA 3. Massas frescas (MFPA) e secas (MSPA) da parte aérea de plantas de manjericão submetidas a diferentes substratos e bandejas. UFGD, Dourados, 2009.

\begin{tabular}{|c|c|c|c|c|c|c|}
\hline \multirow[b]{3}{*}{ Substrato } & \multicolumn{3}{|c|}{ Massa Fresca PA $\left(\mathrm{g} \mathrm{pl}^{-1}\right)$} & \multicolumn{3}{|c|}{ Massa seca PA $\left(\mathrm{g} \mathrm{pl}^{-1}\right)$} \\
\hline & Bandeja & (células) & & Bandeja & (células) & \\
\hline & 72 & 128 & 200 & 72 & 128 & 200 \\
\hline PlantMax Florestais ${ }^{\circledR}$ & $0,16 \mathrm{aB}$ & $0,26 \mathrm{aB}$ & $0,22 \mathrm{aA}$ & $0,04 \mathrm{aB}$ & $0,05 \mathrm{aB}$ & $0,04 \mathrm{aA}$ \\
\hline Tropstrato Vida Verde ${ }^{\circledR}$ & $0,86 \mathrm{aA}$ & $0,59 \mathrm{bA}$ & $0,27 \mathrm{cA}$ & $0,18 \mathrm{aA}$ & $0,09 \mathrm{bA}$ & $0,05 \mathrm{bA}$ \\
\hline PlantMax Hortaliças & $0,19 \mathrm{aB}$ & $0,28 \mathrm{aB}$ & $0,19 \mathrm{aA}$ & $0,03 \mathrm{aB}$ & $0,06 \mathrm{aB}$ & $0,04 \mathrm{aA}$ \\
\hline
\end{tabular}

Letra minúscula compara dados na linha, e letra maiúscula na coluna. Média seguida de mesma letra não difere entre si pelo teste de Tukey a $5 \%$.

TABELA 4. Altura da parte aérea e comprimento de raízes de plantas de manjericão submetidas a diferentes substratos e bandejas. UFGD, Dourados, 2009.

\begin{tabular}{|c|c|c|c|c|c|c|}
\hline \multirow[b]{3}{*}{ Substrato } & \multicolumn{3}{|c|}{ Altura da parte aérea $(\mathrm{cm})$} & \multicolumn{3}{|c|}{ Comprimento de raízes $(\mathrm{cm})$} \\
\hline & Bandeja & (células) & & Bandeja & & \\
\hline & 72 & 128 & 200 & 72 & 128 & 200 \\
\hline PlantMax Florestais $^{\circledR}$ & $4,99 \mathrm{aB}$ & $4,74 \mathrm{aB}$ & $3,56 \mathrm{bB}$ & $257,90 \mathrm{aB}$ & $311,29 \mathrm{aB}$ & $103,99 \mathrm{bA}$ \\
\hline Tropstrato Vida Verde ${ }^{\circledR}$ & $7,95 \mathrm{aA}$ & $7,44 \mathrm{aA}$ & $4,82 \mathrm{bA}$ & 999,44 aA & $842,04 \mathrm{bA}$ & $169,23 \mathrm{cA}$ \\
\hline PlantMax Hortaliças & $3,51 \mathrm{bC}$ & $4,94 \mathrm{aB}$ & $4,96 \mathrm{bB}$ & $116,6 \mathrm{bB}$ & $293,8 \mathrm{aB}$ & $122,2 \mathrm{bA}$ \\
\hline
\end{tabular}

Letra minúscula compara dados na linha, e letra maiúscula na coluna. Média seguida de mesma letra não difere entre si pelo teste de Tukey a $5 \%$.

a superioridade do substrato Tropstrato Vida Verde $^{\circledR}$ acondicionado na bandeja de 72 células. Considerando somente o substrato Tropstrato Vida Verde ${ }^{\circledR}$, mudas acondicionadas na bandeja de 72 células $(994,64 \mathrm{~cm})$ tiveram comprimento de raízes 20 e $499 \%$ maiores que as mudas acondicionadas nas bandejas de $128(830,03 \mathrm{~cm}) \mathrm{e}$ 200 células $(161,07 \mathrm{~cm})$, respectivamente. Avaliando o comprimento das raízes nos diferentes substratos na bandeja de 72 células, observou-se que a superioridade do Tropstrato Vida Verde ${ }^{\circledR}(994,64$ $\mathrm{cm}$ ) foi de 263 e $833 \%$ comparado ao substrato PlantMax Florestais ${ }^{\circledR}$ e PlantMax Hortaliças $\mathrm{HA}^{\circledR}$ (273,9 e 106,62 cm, respectivamente) (Tabela 5). Para a massa fresca e seca do sistema radicular, analisando somente o uso do substrato Tropstrato Vida Verde ${ }^{\circledR}$ na bandeja com melhor ganho de massa (bandeja de 72 células), houve um aumento de 304 e $564 \%$ na massa fresca, e 350 e $575 \%$ na massa seca de raízes em relação o substrato PlantMax Florestais ${ }^{\circledR}$ e PlantMax Hortaliças $\mathrm{HA}^{\circledR}$, respectivamente. Os outros dois substratos (PlantMax Florestais ${ }^{\circledR}$ e PlantMax Hortaliças $\mathrm{HA}^{\circledR}$ ) não proporcionaram diferenças significativas para massa fresca, seca e comprimento do sistema radicular das mudas em função do tipo de bandeja utilizada.

Os resultados observados na presente pesquisa corroboram com as informações da literatura as quais relatam que os tipos de substrato e de bandeja influenciam diretamente no crescimento e desenvolvimento das mudas. À medida que as mudas se desenvolvem, bandejas que acomodam pequenas quantidades de substratos, 

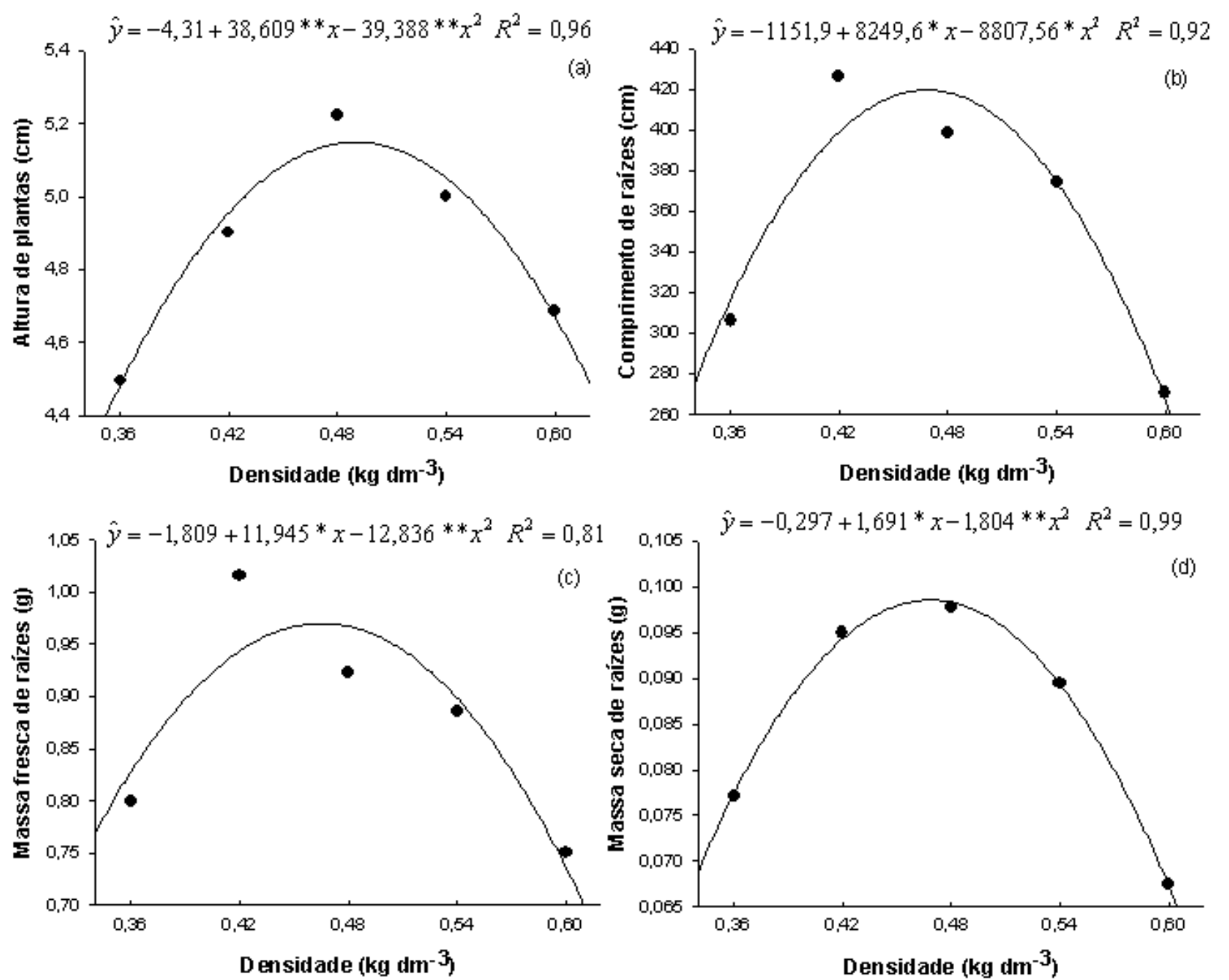

FIGURA 1. Altura da parte aérea (a), comprimento (b), massa fresca (c) e seca (d) do sistema radicular de plantas de manjericão submetidas a diferentes densidades. UFGD, Dourados, 2009.

TABELA 5. Massas frescas (MFSR) e secas (MSSR) do sistema radicular de plantas de manjericão submetidas a diferentes substratos e bandejas. UFGD, Dourados, 2009.

\begin{tabular}{|c|c|c|c|c|c|c|}
\hline \multirow[b]{3}{*}{ Substrato } & \multicolumn{3}{|c|}{ Massa fresca de raízes $\left(\mathrm{g} \mathrm{pl}^{-1}\right)$} & \multicolumn{3}{|c|}{ Massa seca de raízes $\left(\mathrm{g} \mathrm{pl}^{-1}\right)$} \\
\hline & \multicolumn{3}{|c|}{ Bandeja (células) } & \multirow{2}{*}{$\begin{array}{c}\text { Bandeja } \\
72\end{array}$} & \multirow{2}{*}{$\begin{array}{r}\text { (células) } \\
128\end{array}$} & \multirow[b]{2}{*}{200} \\
\hline & 72 & 128 & 200 & & & \\
\hline PlantMax Florestais ${ }^{\circledR}$ & $0,71 \mathrm{aB}$ & $0,85 \mathrm{aB}$ & $0,22 \mathrm{bB}$ & $0,08 \mathrm{aB}$ & $0,08 \mathrm{aA}$ & $0,03 \mathrm{bA}$ \\
\hline Tropstrato Vida Verde ${ }^{\circledR}$ & $2,65 \mathrm{aA}$ & $1,79 \mathrm{bA}$ & $0,52 \mathrm{cA}$ & $0,32 \mathrm{aA}$ & $0,18 \mathrm{bB}$ & $0,06 \mathrm{cA}$ \\
\hline PlantMax Hortaliças & $0,39 \mathrm{bB}$ & $0,77 \mathrm{aB}$ & $0,38 \mathrm{bAB}$ & $0,04 \mathrm{aB}$ & $0,08 \mathrm{aB}$ & $0,05 \mathrm{aA}$ \\
\hline
\end{tabular}

Letra minúscula compara dados na linha, e letra maiúscula na coluna. Média seguida de mesma letra não difere entre si pelo teste de Tukey a $5 \%$. 
disponibilizariam pequenas quantidades de nutrientes e água, os quais se esgotam em períodos cada vez mais curtos, gerando stress nas plantas o que limita o crescimento e desenvolvimento. Com outras olerícolas, também se constatou que o tamanho das células da bandeja interfere na produção de mudas, sendo melhor desempenho das mudas obtidas com bandejas com maiores volumes internos e, menores números de células. Experimentos, com alface (Trani et al., 2004), cebola (Reghin et al., 2007a), chicória (Reghin et al., 2006, Reghin et al., 2007b), e tomate cereja (Lima et al., 2009) demonstraram que as mudas dessas plantas apresentam melhor qualidade quando produzidas em células com maior volume. Objetivando estudar a viabilidade da utilização de bandejas de poliestireno expandido com 72 e 128 células, na produção de mudas de batata-doce com boa sanidade, utilizando o substrato comercial Plantmax ${ }^{\circledR}$, Rós \& Narita (2011) constataram que o tipo de bandeja apresentou influência na produtividade de ramas (peso de ramas frescas), a qual foi favorecida pela bandeja de 72 células com aumento na produção de mudas $16 \%$ em relação às de 128 células.

O melhor desempenho do substrato Tropstrato Vida Verde ${ }^{\circledR}$, tanto para desenvolvimento da parte aérea quanto para o sistema radicular, pode estar relacionado à manutenção da umidade $(60 \%)$ e baixa densidade $\left(200 \mathrm{~kg} \mathrm{~m}^{-3}\right.$ ) (Tabela 1 ), o que proporciona melhor desenvolvimento das raízes em relação ao PlantMax Florestais ${ }^{\circledR} \mathrm{e}$ PlantMax Hortaliças $\mathrm{HA}^{\circledR}$ (com $50 \%$ de umidade; retenção de água de $150 \%$ e densidade de 450 $\mathrm{kg} \mathrm{m}^{-3}$, para ambos os substratos). Substratos são meios porosos, formados por sólidos e poros preenchidos por água e ar (Kämpf, 2001). Os poros são responsáveis pelas trocas gasosas entre o substrato e a atmosfera, bem como determinam os movimentos da água no vaso e a drenagem. Portanto, substrato com densidade menor, proporciona maior porosidade, melhor drenagem e menor restrição física ao crescimento e desenvolvimento das plantas. Outro aspecto importante na composição dos substratos é o conteúdo de matéria orgânica, presentes como casca de pinus e turfa (Tabela 1) elevando a capacidade de retenção de água, proporcionando melhor estruturação, aeração, estabilidade de agregados e disponibilidade de nutrientes, produzindo assim mudas mais vigorosas.

Notou-se também que esse substrato não possui corretivos da acidez, e com a menor quantidade de íons na solução do solo, diminuiu a condutividade elétrica (CE) do substrato Tropstrato Vida Verde ${ }^{\circledR}\left(0,5 \mathrm{dS} \mathrm{cm}^{-1}\right)$ (Tabela 1). Os valores de CE são proporcionais à concentração dos vários íons em solução, e da mesma forma ao potencial osmótico da mesma. A absorção de água e nutriente através do sistema radicular, e a produção de parte aérea e frutos pelas plantas, são influenciados pelo potencial osmótico do meio nutritivo (Bresler \& Hoffman, 1986; Huett, 1994; Costa et al. 2001; Freire et al., 2010). De acordo com Taiz \& Zeiger (2002), o aumento da concentração salina aumenta a pressão osmótica no meio fazendo com que, mesmo em ambiente com água disponível como é a solução nutritiva, a planta tenha dificuldade em absorver água suficiente para repor a perda por transpiração e também os nutrientes, fato que prejudica o desenvolvimento tanto da parte aérea quanto do sistema radicular.

Independente do substrato ou tipo de bandeja, a densidade que proporcionou maior comprimento $(410 \mathrm{~cm})$, massa fresca $(0,96 \mathrm{~g}$ planta $\left.{ }^{-1}\right)$ e massa seca $\left(0,10\right.$ g planta $\left.^{-1}\right)$ do sistema radicular foi $0,47 \mathrm{~g} \mathrm{dm}^{-3}$ (Figuras $1 \mathrm{~b}, \mathrm{c}, \mathrm{d}$ ). Kämpf (2000) e Sampaio et al. (2008) relatam que as propriedades físicas mais importantes para um substrato são a densidade do substrato, a porosidade total, o espaço de aeração e a retenção de água. Quanto mais alta a densidade, mais difícil fica o cultivo no recipiente, principalmente por limitações no crescimento radicular. Analisando arisco, areia, esterco bovino e húmus de minhoca em diferentes combinações como substrato para o desenvolvimento de mudas de manjericão, Paiva et al. (2011) observaram maior comprimento do sistema radicular em arisco, e atribuíram esse acréscimo devido a menor densidade, elevação do percentual de porosidade total, espaço de aeração e água facilmente disponível dos substratos, enquanto que, um aumento da densidade dos substratos causou redução no comprimento das raízes.

A formação de mudas comerciais de boa qualidade envolve os processos de germinação de sementes, iniciação radicular e formação do sistema radicular e parte aérea, que estão diretamente relacionados com características que definem o nível de eficiência dos substratos, tais como aeração, drenagem, retenção de água e disponibilidade balanceada de nutrientes. Por sua vez, à medida que a densidade aumenta as características dos substratos são altamente modificadas entre si, especialmente a macroporosidade, responsável pela aeração e drenagem que é reduzida, e a microporosidade e retenção de água, que são aumentadas consideravelmente, o que gera um menor volume de substrato explorado, consequentemente menor absorção de água e nutrientes de extrema importância para o crescimento e desenvolvimento 
das mudas de manjericão.

Nas condições em que foi conduzido o experimento concluiu-se que o substrato a ser utilizado na produção das mudas de manjericão e o tipo de bandeja influenciam diretamente no crescimento e desenvolvimento das mudas. A produção de mudas comerciais de manjericão (Ocimum basilicum L.) foi melhor com o uso do substrato Tropstrato Vida Verde ${ }^{\circledR}$ na bandeja de 72 células associado com a densidade de $0,47 \mathrm{~g} \mathrm{dm}^{-3}$.

\section{REFERÊNCIA}

BRESLER, E.; HOFFMAN, G.J. Irrigation management for soil salinity control: theories and tests. Soil Science Society of America Journal, v.50, p.1552-1560, 1986.

BRITO, M.R.; SENNA-VALLE, L. Plantas medicinais utilizadas na comunidade Caiçara da Praia do Sono, Paraty, Rio de Janeiro, Brasil. Acta Botânica Brasilica, v. 25, n.2, p.363-372, 2011.

COSTA, P.C. et al. Condutividade elétrica da solução nutritiva e produção de alface em Hidroponia. Scientia Agricola, v.58, n.3, p.595-597, 2001.

ECHER, M.M. et al. Avaliação de mudas de beterraba em função do substrato e do tipo de bandeja. Semina: Ciências Agrárias, v.28, n.1, p. 45-50, 2007.

FREIRE, A.L.O. et al. Crescimento, acúmulo de íons e produção de tomateiro irrigado com água salina Semina: Ciências Agrárias, v. 31, suplemento 1, p. 1133-1144, 2010

GORDIN, C.R.B. et al. Diferentes combinações de substrato comercial e húmus na formação de mudas de chicória. Revista Brasileira de Agroecologia, v. 3, p. 138-141- Suplemento especial, 2008.

HUETT, D.O. Growth, nutrient uptake and tipburn severity of hidroponic lettuce in response to electrical conductivity and $\mathrm{K}: \mathrm{Ca}$ ratio in solution. Australian Journal of Agricultural Research, v.45, p.251-67, 1994.

KÄMPF, A.N. Substratos para plantas: um desafio para a ciência do solo. Revista Opinião, v.26, n.1, p.5-16, 2001

LIMA, C.J.G.S. et al. Avaliação de diferentes bandejas e substratos orgânicos na produção de mudas de tomate cereja. Revista Ciência Agronômica, v.40, n.1, p.123128, 2009.

LORENZI, H.; MATOS, F.J.A. Plantas medicinais do Brasil: nativas e exóticas. Nova Odessa: Instituto Plantarum, 2002. 544 p.

MARSH, L.A.R. Measurement of length in random arrangement of lines. Journal of Applied Ecology, v.8, n.1, p.265-7, 1971.

MENEZES JÚNIOR, F.O.G. et al. Caracterização de diferentes substratos e seu desempenho na produção de mudas de alface em ambiente protegido. Horticultura Brasileira, v.18, n.3, p.164-170, 2000.

MOSCA, V.P.; LOIOLA, M.I.B. Uso popular de plantas medicinais no Rio Grande do Norte, Nordeste do Brasil. Revista Caatinga, Mossoró, v.22, n.4, p.225-234, 2009.

NESMITH, D.S.; DUVAL, J.R. The effect of container size. HortTechnology, v.8, n.4, p.495-98, 1998.
PAIVA, E.P. et al. Composição do substrato para o desenvolvimento de mudas de manjericão (Ocimum basilicum L.). Revista Caatinga, v. 24, n. 4, p. 62-67, 2011.

PEREIRA, P.R.G.; MARTINEZ, H.E.P. Produção de mudas para o cultivo de hortaliças em solo e hidroponia. Informe Agropecuário, v.20, p.24-31, 1999.

POLITEO, O.; JUKIC, M.; MILOS, M. Chemical composition and antioxidant capacity of free volatile aglycones from basil (Ocimum basilicum L.) compared with its essential oil. Food Chemistry, v.101, n.1, p.379-385, 2007.

REGHIN, M.Y. et al. Efeitos do tipo de bandejas e de cultivares na produção de plântulas e no rendimento da chicória. Ciência e Agrotecnologia, v.30, n.3, p.435-443, 2006.

REGHIN, M.Y. et al. Viabilidade do sistema de produção de mudas em bandejas em três cultivares de cebola. Ciência e Agrotecnologia, v.31, n.4, p.1075-1084, 2007a.

REGHIN, M.Y. et al. Produtividade da chicória (Cichorium endivia L.) em função de tipos de bandejas e idade de transplante de mudas. Ciência e Agrotecnologia, v.31, n.3, p.739-747, 2007b.

RESENDE, G.M. et al. Efeitos de tipos de bandejas e idade de transplantio de mudas sobre o desenvolvimento e produtividade de alface americana. Horticultura Brasileira, v.21, n.3, p.558-63, 2003

RIBEIRO JÚNIOR, J.I. Análises estatísticas no SAEG. Viçosa: UFV, 2001. 301p.

RODRIGUES, E.T. et al. Produção de mudas de tomateiro em diferentes substratos e recipientes em ambiente protegido. Horticultura Brasileira, v. 28 n.4, p.483488, 2010.

RÓS A. B.; NARITA, N. Produção de mudas de batatadoce a partir de poucas plantas matrizes. Revista Brasileira de Ciências Agrárias, v.6, n.1, p.85-59, 2011.

SAMPAIO, R.A. et al. Produção de mudas de tomateiro em substratos contendo fibra de coco e pó de rocha. Horticultura Brasileira, v. 26, n. 4, p. 499-503, 2008.

SARTORATOTTO, A. et al. Composition and antimicrobial activity of essential oils from aromatic plants used in Brazil. Brazilian Journal of Microbiology, v.35, p.275280, 2004

SILVA, A.C.R. et al. Produção de mudas de alface com vermicompostos em diferentes tipos de bandeja. Horticultura Brasileira, v.18, p.512-13, 2000.

TAIZ, L.; ZEIGER, E. Plant physiology. 3.ed. Sunderland: Sinauer Associates, 2002. 690p.

TEIXEIRA, J.P.F. et al. Essential oil contents in two cultivars of basil cultivated on NFT-hydroponics. In: Proceedings of the First Latin-American Symposium on the Production of Medicinal, Aromatic and Condiments Plants, Acta Horticulturae, v.569, p. 203-208, 2002.

TENNANT, D.A. Test of a modified line intersect of estimating root length. Journal Ecology, v.32, p.9951001, 1975.

TRANI, P.E. et al. Avaliação de substratos para produção de mudas de alface. Horticultura Brasileira, v. 25, n.2 p. 256-260, 2007.

TRANI, P.E. et al. Produção de mudas de alface em bandejas e substratos comerciais. Horticultura Brasileira, v.22, n.2, p.290-294, 2004.

Rev. Bras. PI. Med., Campinas, v.16, n.1, p.10-17, 2014 